\title{
ANALISA PRODUKTIFITAS ALAT BERAT PADA PROYEK PEMBANGUNAN GEDUNG FAKULTAS SYARIAH DAN ILMU HUKUM IAIN TULUNGANGUNG
}

\author{
Aprilia Kaprina ${ }^{* 1}$, Sigit Winarto ${ }^{2}$, Yosef Cahyo SP. ${ }^{3}$ \\ 1,2,3 Fakultas Teknik, Universitas Kadiri. \\ e-mail:*124aprilhantoto@gmail.com,2sigit.winarto@unik-kediri.ac.id, \\ 3 yosef.cs@unik-kediri.ac.id.
}

\begin{abstract}
Heavy equipment is an essential factor in large-scale construction projects. Heavy equipment used in civil engineering is a tool used to assist humans in carrying out development work, and the analysis of the productivity of heavy equipment is calculated so that its use is more efficient in terms of time and operational costs. This project functions as a building for lecture activities, and the land has a total building area of 22,983 $\mathrm{m}$ 2. The types of heavy equipment used for earthwork and structural work are excavators, dump trucks, and tower cranes. Based on the results of the calculation of the heavy equipment productivity analysis, which includes earthworks and tower crane work structures, it is obtained the results of research on heavy equipment that are precise, short time. It can be used so that all heavy equipment can work optimally. Of the several combinations, Combination III is the most effective and time-efficient in completing excavation, stockpiling, and tower crane work structures, namely 2 Excavator units, 4 Dumptruck, and 1 Tower Crane. The time needed to do this job is 251.52 hours, with a heavy equipment cost of IDR 276,422,572.00 and the amount of human resource analysis of IDR 9,555,249,830.00.
\end{abstract}

Keywords : $\quad$ Heavy equipment, efficiency, time, cost.

\begin{abstract}
Abstrak
Alat berat merupakan faktor penting di dalam proyek konstruksi berskala besar. Alat berat yang digunakan dalam ilmu teknik sipil adalah alat yang digunakan untuk membantu manusia dalam melakukan pekerjaan pembangunan dan diperhitungkan analisa produktifitas alat berat agar penggunaannya lebih efisiensi dari segi waktu dan biaya operasionalnya. Proyek ini berfungsi sebagai bangunan tempat untuk aktifitas perkuliahan dan tanah memiliki luas total bangunan sebesar $22.983 \mathrm{~m}^{2}$. Jenis alat berat yang digunakan untuk pekerjaan tanah dan pekerjaan struktur ialah Excavator, Dumptruck, dan Tower Crane. Berdasarkan hasil perhitungan analisa produktifitas alat berat yang meliputi pekerjaan pekerjaan tanah dan pekerjaan struktur kerja tower crane diperoleh hasil penelitian alat berat yang tepat, waktu yang singkat dan dapat digunakan agar seluruh alat berat dapat bekerja optimal. Dari beberapa kombinasi, di Kombinasi III yang paling efektif dan efisien waktu pelaksanaannya dalam menyelesaikan pekerjaan galian, timbunan dan pekerjaan struktur kerja tower crane yaitu 2 unit Excavator, 4 Dumptruck, dan 1 Tower Crane. Waktu yang dibutuhkan untuk melakukan pekerjaan tersebut adalah 251,52 jam dengan biaya alat berat sebesar $\mathrm{Rp}$ 276.422.572,00 dan jumlah analisa sumber daya manusia sebesar Rp 9.555.249.830,00.
\end{abstract}

Kata Kunci : $\quad$ Alat berat, efisien, waktu, biaya. 


\section{PENDAHULUAN}

\subsection{Latar Belakang}

Pada umumnya setiap pelaksanaan pekerjaan bangunan bertingkat dalam bidang konstruksi merupakan pekerjaan yang sangat penting untuk mencapai keberhasilan suatu proyek, [1][2]. Dalam pekerjaan suatu proyek diperlukan pemakaian alat berat jika pekerjaan cukup besar dan memerlukan atau membutuhkan kecepatan pelaksanaan pekerjaan sesuai jadwal atau target yang sudah ditentukan, [3][4]. Untuk mempermudah dan mempercepat pekerjaan tersebut maka digunakan alat berat yang berupa excavator, dump truck dan tower crane, [5] Dalam menentukan kebutuhan penggunaan alat berat sebaiknya memperhatikan kondisi tanah dilapangan dan banyaknya volume pekerjaan yang dikerjakan dan menganalis biaya sehingga perbandingan jumlah alat berat yang akan digunakan sesuai dengan kebutuhan yang diperlukan, [6]. Penggunaan alat berat yang kurang tepat dengan kondisi dan situasi lapangan pekerjaan akan berpengaruh pada rendahnya produktifitas alat dan tidak tercapainya jadwal atau target yang sudah ditentukan, [7][8]. Oleh karena itu, perlu mempertimbangkan jenis, kapasitas, volume dan fungsi alat berat sehingga akan meminimalisir penggunaan alat berat yang kurang optimal dan perlu dilakukan analisa perencanaan yang tepat sehingga penggunaannya lebih efisien dari segi waktu dan biaya operasionalnya, [9]. Inilah alasan penyusun memilih topik untuk menganalisa produktifitas alat berat pada proyek

\subsection{Rumusan Masalah}

Berdasarkan uraian latar belakang diatas, maka permasalahan yang akan dibahas pada penulisan ini adalah :

1. Bagaimana penggunaan alat berat excavator, dumptruck, dan tower crane dalam proyek tersebut?

2. Berapa kapasitas pekerjaan yang digunakan sesuai penggunaan alat berat excavator, dumptruck, dan tower crane dalam proyek tersebut ?

3. Berapa anggaran biaya yang dikeluarkan agar diperoleh nilai produktifitas yang efektif dan efisien dalam penggunaan alat tersebut?

Dan tujuan dari penelitian ini adalah untuk menganalisis anggaran biaya sesuai analisa SNI (Standart Nasional Indonesia), Alat berat yang digunakan berupa excavator, dump truck dan tower crane, serta efesiensi penggunaan alat berat.

\section{METODE PENELITIAN}

\subsection{Metodologi Penelitian}

Metodologi yang digunakan dalam penelitian ini menggunakan metode deskripsi analisis. 
Dimana metode ini bertujuan untuk mendeskripsikan atau memberi gambaran terhadap suatu obyek penelitian yang diteliti melalui data yang telah terkumpul dan membuat kesimpulan. Alur penelitian seperti berikut : Pengambilan data yang mendukung secara langsung kepaada pelaksanaan proyek Pembangunan Gedung, Pengolahan data dengan maksud data apa saja yang diperlukan :

a. Biaya Sewa Alat

b. Waktu Efektif Pelaksanaan Pekerjaan

c. Volume Pekerjaan

d. Volume Pekerjaan Tanah

e. Jenis / Spesifikasi dan Fungsi Alat Berat.

\subsection{Alat Berat}

Alat-alat berat yang sering dikenal di dalam ilmu Teknik Sipil merupakan alat yang digunakan untuk membantu manusia dalam melakukan pekerjaan pembangunan suatu struktur bangunan. Alat berat merupakan faktor penting di dalam proyek, terutama proyek-proyek konstruksi maupun pertambangan dan kegiatan lainnya dengan skala yang besar, [10][11][12]. Tujuan dari penggunaan alat-alat berat tersebut adalah untuk memudahkan manusia dalam mengerjakan pekerjaannya, sehingga hasil yang diharapkan dapat tercapai dengan lebih mudah dengan waktu yang relatif lebih singkat, [13]. Setiap perusahaan atau organisasi dalam menjalankan aktivitas / usahanya, pasti dihadapkan pada teknologi yang akan mencerminkan kekuatan perusahaan dalam mencapai tujuan. Maka dari itu setiap perusahaan berlomba-lomba dalam hal teknologi salah satunya penggunaan alat berat guna mencapai sasaran. Menurut Ir. Susy Fatena Rostyanti Msc dalam bukunya Alat Berat Untuk Proyek Konstruksi (2008), [14] menyebutkan bahwa bonafiditas suatu perusahaan konstruksi tergantung dari aset-aset teknologi yang dimiliknya, salah satunya adalah alat berat. Alat berat yang dimiliki sendiri oleh perusahaan konstruksi akan sangat menguntungkan dalam memenangkan tender proyek konstruksi secara otomatis akan mencerminkan kekuatan perusahaan tersebut, [15][16].

\subsection{Faktor - faktor Yang Mempengaruhi Produktifitas Alat Berat}

3.3.1 Excavator dan Dumptruck,.

a. Faktor Kondisi Peralatan

b. Faktor Kondisi Medan dan Faktor Material

c. Koefisiensi Traksi

d. Faktor Operator dan Mekanik

e. Faktor Cuaca

f. Faktor Manajemen 
g. Job Faktor

3.3.2 Tower Crane

a. Kondisi Alat

b. Kondisi Lapangan

c. Faktor Manajemen

d. Kemampuan Operator

\subsection{Biaya Operasional Alat Berat}

Biaya operasional adalah merupakan biaya-biaya yang harus dikeluarkan agar alat dapat bekerja, [17][18] berikut adalah biaya yang harus dikeluarkan :

A. Biaya Operasional Excavator dan Dump Truck.

1. Biaya bahan bakar

2. Biaya Oli pelumas

3. Biaya bahan hidroulic

4. Biaya bahan gemuk

5. Biaya bahan pokok

6. Biaya operator

7. Biaya pemeliharaan perbaikan

8. Biaya Mobilisasi dan Demobilisasi

B. Biaya Operasional Tower Crane

1. Biaya Bahan Bakar

2. Biaya Pelumas

3. Biaya Listrik

4. Biaya Operator Alat

5. Biaya Erection - Dismantle

6. Biaya Mobilisasi dan Demolisasi

\subsection{Efisiensi Alat}

Dalam pelaksanaan pekerjaan dengan jangka waktu penyelesaian pekerjaan dalam suatu hari kalender. Oleh karena itu, maka peralatan yang digunakan harus dapat menyesaikan pekerjaan tepat waktu dengan terlebih dahulu menetapkan hari kerja efekif, sehingga target penyelesaian persatu-satuan waktu dapat diketahui, [19][20]. Dengan begitu jumla unit peralatan perkegiatan dapat dihitung dengan rumus sebagai berikut : 
$\mathrm{N}=$ We $\times \mathrm{S} \times \mathrm{Q} \mathrm{V}$

Dimana : $\mathrm{N}=$ Jumlah Peralatan (unit)

$\mathrm{V}=$ Volume pekerjaan $(\mathrm{m} 3)$

We $=$ Waktu efektifitas kerja (hari)

$\mathrm{S}=$ Standart kerja efektifitas perhari alat (jam/hari)

$\mathrm{Q}=$ Produksi alat per satu-satuan waktu (m3/jam).

\subsection{Faktor Yang Mempengaruhi Produktifitas Alat.}

Menggunakan alat berat terdapat faktor yang mempengaruhi produktifitas alat, yaitu efisiensi alat dimana efektifitas alat tersebut bekerja tergantung dari beberapa hal antara lain:

1. Kemampuan operator pemakai alat.

2. Pemilihan dan pemeliharaan alat.

3. Perencanaan dan pengaturan letak alat.

4. Topografi dan volume pekerjaan.Kondisi cuaca.

\subsection{Metodologi Penelitian}

Metodologi yang digunakan dalam penyelesaian tugas akhir ini menggunakan metode deskripsi analisis. Dimana metode ini bertujuan untuk mendeskripsikan atau memberi gambaran terhadap suatu obyek penelitian yang diteliti melalui data yang telah terkumpul dan membuat kesimpulan.

1. Pengambilan data yang mendukung secara langsung kepaada pelaksanaan proyek Pembangunan Gedung.

2. Pengolahan data dengan maksud data apa saja yang diperlukan :
a. Biaya Sewa Alat
b. Waktu Efektif Pelaksanaan Pekerjaan
c. Volume Pekerjaan
d. Volume Pekerjaan Tanah
e. Jenis / Spesifikasi dan Fungsi Alat Berat.

\section{HASIL DAN PEMBAHASAN}

\subsection{Analisa Hasil}

\subsubsection{Perhitungan kapasitas produksi alat berat}

1. Perhitungan waktu siklus Waktu Siklus 
= waktu muat + waktu angkat + waktu bongkar + waktu kembali

$=5+0,197+7+0,152=12,349$ menit

2. Perhitungan Excavator / Backhoe

a. Waktu siklus (Cms) dimana kondisi pemuatan diasumsikan sedang,

$\mathrm{Cms}=$ Waktu siklus (detik)

$\mathrm{E}=$ Efisiensi kerja,

dimana:

$$
\begin{aligned}
\mathrm{E} & =\mathrm{E} c \mathrm{x} \text { Eam } \times \mathrm{Em} \times \mathrm{EM} \\
& =0,85 \times 0,805 \times 1,20 \times 0,90=0,74
\end{aligned}
$$

3. Perhitungan waktu pelaksanaan Tower crane diasumsikan kondisi sedang dan pemeliharaan mesin sedang,

sehingga :

Efisiensi $=0,65$ (data terlampir)

Volume $=1,2 \mathrm{~m} 3$ (data terlampir)

Produksi per siklus $=0,8 \mathrm{~m} 3$

Waktu siklus $=12,349$ menit

Produksi perjam $=0.8 \times \frac{60}{12.349} \times 0.65=2,527 \mathrm{~m}^{3} / \mathrm{jam}$

Waktu pelaksanaan $=\frac{1.2 \mathrm{~m}^{3}}{2.527 \mathrm{~m}^{3} / \mathrm{jam}}=0.475 \mathrm{jam}$

\subsubsection{Pengolahan Analisa Perhitungan Berdasarkan Waktu dan Biaya Setiap Kombinasi.}

\begin{tabular}{|c|c|c|c|}
\hline $\mathrm{AB}$ & $\begin{array}{c}\text { Harga Sewa } \\
\quad(\text { jam })\end{array}$ & $\begin{array}{c}\text { Jam } \\
\text { Operasi }\end{array}$ & $\begin{array}{c}\text { Total Harga } \\
\text { Sewa }\end{array}$ \\
\hline 1Ex & Rp.335.000 & 40,98 & Rp13.728.300 \\
\hline $1 \mathrm{Dt}$ & Rp. 190.400 & 132,69 & Rp25.264.176 \\
\hline $1 \mathrm{Tc}$ & Rp1.200.000 & 197,86 & Rp237.432.000 \\
\hline & Total & 371,53 & Rp276.424.476 \\
\hline
\end{tabular}

Tabel 1. Kombinasi I

Sumber : Analisa Perhitungan

Tabel 2. Kombinasi II

\begin{tabular}{|c|c|c|c|}
\hline AB & $\begin{array}{c}\text { Harga Sewa } \\
\text { (jam) }\end{array}$ & $\begin{array}{c}\text { Jam } \\
\text { Operasi }\end{array}$ & $\begin{array}{c}\text { Total Harga } \\
\text { Sewa }\end{array}$ \\
\hline 2Ex & Rp.335.000 & 20,49 & Rp.13.728.300 \\
\hline 3Dt & Rp. 190.400 & 44,23 & Rp.25.264.176 \\
\hline 1Tc & Rp.1.200.000 & 197,86 & Rp237.432.000 \\
\hline \multicolumn{2}{|c|}{ Total } & 262,58 & Rp276.424.476 \\
\hline
\end{tabular}

Sumber : Analisa Perhitungan 
Tabel 3. Kombinasi III

\begin{tabular}{|c|c|c|c|}
\hline AB & $\begin{array}{c}\text { Harga Sewa } \\
\text { (jam) }\end{array}$ & $\begin{array}{c}\text { Jam } \\
\text { Operasi }\end{array}$ & $\begin{array}{c}\text { Total Harga } \\
\text { Sewa }\end{array}$ \\
\hline 2Ex & Rp.335.000 & 20,49 & Rp.13.728.300 \\
\hline 4Dt & Rp. 190.400 & 33,17 & Rp.25.262.176 \\
\hline 1Tc & Rp.1.200.000 & 197,86 & Rp.237.432.000 \\
\hline
\end{tabular}

Sumber : Analisa Perhitungan

Tabel 4. Kombinasi IV

\begin{tabular}{|c|c|c|c|}
\hline $\mathrm{AB}$ & $\begin{array}{l}\text { Harga } \\
\text { Sewa }\end{array}$ & $\begin{array}{c}\text { Jam } \\
\text { Operasi }\end{array}$ & $\begin{array}{c}\text { Total Harga } \\
\text { Sewa }\end{array}$ \\
\hline $3 \mathrm{Ex}$ & Rp.335.000 & 13,66 & Rp13.728.300 \\
\hline $3 \mathrm{Dt}$ & $\begin{array}{c}\text { Rp. } \\
190.400\end{array}$ & 44,23 & Rp25.262.176 \\
\hline $1 \mathrm{Tc}$ & Rp1.200.00 & 197,86 & Rp237.432.000 \\
\hline \multicolumn{2}{|c|}{ Total } & 255,75 & Rp276.422.572 \\
\hline
\end{tabular}

Sumber : Analisa Perhitungan

\subsubsection{Analisa Perhitungan Berdasarkan Sumber Daya Manusia}

Tabel 4. Perhitungan Sumber Daya Manusia

\begin{tabular}{|c|c|c|c|}
\hline Komb & Vol. (M3) & $\begin{array}{c}\text { Tot. } \\
\text { Waktu } \\
\text { (jam) }\end{array}$ & Harga Satuann \\
\hline K I & 5215,86 & 371,53 & Rp. 37.763.470 \\
\hline K II & 5215,86 & 262,58 & Rp. 37.942.420 \\
\hline K III & 5215,86 & 251,52 & Rp. 37.990.020 \\
\hline K IV & 5215,86 & 255,75 & Rp. 38.026.170 \\
\hline
\end{tabular}

Sumber : Analisa Perhitungan 


\subsubsection{Analisa Hasil Anggaran Biaya dan Waktu pada Masing-masing Kombinasi}

Tabel 5. Hasil Anggaran Biaya dan Waktu pada Masing-masing Kombinasi.

\begin{tabular}{|c|c|c|c|c|}
\hline Komb & $\begin{array}{c}\text { Vol. } \\
\text { (M3) }\end{array}$ & $\begin{array}{c}\text { Tot. } \\
\text { (jam) }\end{array}$ & $\begin{array}{c}\text { Harga } \\
\text { Satuan }\end{array}$ & $\begin{array}{c}\text { Total Harga } \\
\text { Satuann }\end{array}$ \\
\hline K I & 5215,86 & 371,53 & $\begin{array}{c}\text { Rp. } \\
37.763 .470\end{array}$ & $\begin{array}{c}\text { Rp. } \\
14.030 .262 .009\end{array}$ \\
\hline K II & 5215,86 & 262,58 & $\begin{array}{c}\text { Rp. } \\
37.942 .420\end{array}$ & $\begin{array}{c}\text { Rp. } \\
9.962 .920 .644\end{array}$ \\
\hline K III & 5215,86 & 251,52 & $\begin{array}{c}\text { Rp. } \\
37.990 .020\end{array}$ & $\begin{array}{c}\text { Rp. } \\
\text { 9.555.249.830 }\end{array}$ \\
\hline K IV & 5215,86 & 255,75 & $\begin{array}{c}\text { Rp. } \\
38.026 .170\end{array}$ & $\begin{array}{c}\text { Rp. } \\
\text { R. }\end{array}$ \\
\hline
\end{tabular}

Sumber : Analisa Perhitungan

\section{KESIMPULAN}

Dari perhitungan analisa produktfitas pelaksanaan pada Proyek Pembangunan Gedung Fakultas Syariah dan Ilmu Hukum IAIN Tulungagung dapat disimpulkan sebagai berikut :

a. Menggunakan Kombinasi I yaitu 2 unit Excavator, 3 Dumptruck, dan 1 TowerCrane Crane. Waktu yang dibutuhkan untuk melakukan pekerjaan tersebut adalah 371,53 jam dengan biaya sebesar Rp.276.424.476,00 dan jumlah analisa sumber daya manusia sebesar Rp.14.030.262.009,00.

b. Menggunakan Kombinasi II yaitu 2 unit Excavator, 3 Dumptruck, dan 1 TowerCrane waktu yang dibutuhkan untuk melakukan pekerjaan tersebut adalah 262,58 jam dengan biaya sebesar Rp. 276.424.476,00 dan jumlah analisa sumber daya manusia sebesar Rp.9.962.920.644,00.

c. Menggunakan Kombinasi III yaitu 2 unit Excavator, 4 Dumptruck dan 1 Tower Crane. Waktu yang dibutuhkan untuk melakukan pekerjaan tersebut adalah 251,52 jam dengan biaya sebesar Rp.276.422.572,00 dan jumlah analisa sumber daya manusia sebesar Rp.9.555.249.830,00.

d. Menggunakan Kombinasi IV yaitu 3 unit Excavator, 3 Dumptruck, dan 1 Tower Crane. Waktu yang dibutuhkan untuk melakukan pekerjaan tersebut adalah 255,75 jam dengan biaya sebesar Rp.276.424.476,00 dan jumlah analisa sumber daya manusia sebesar Rp.9.725.192.978,00. 
Dari beberapa kombinasi, di Kombinasi III yang paling efektif dan efisien waktu pelaksanaannya dalam menyelesaikan pekerjaan galian, timbunan dan pekerjaan struktur kerja tower crane pada Proyek Pembangunan Gedung Fakultas Syariah dan Ilmu Hukum IAIN Tulungagung.

\section{SARAN}

Dalam menghitung atau menganalisa produktifitas suatu pekerjaan proyek bangunan bertingkat pada penggunaan atau pemilihan alat berat perlu diperhatikan lokasi maupun kondisi proyek, rencana dari proyek meliputi waktu dan biaya serta metode kerja dari alat berat sendiri. Pembahasan dibatasi pada perhitungan analisa produktifitas alat berat untuk pekerjaan galian, timbunan dan pekerjaan struktur kerja tower crane. Maka dari itu dilakukan perhitungan dengan metode yang tepat sehingga akan mempermudah menemukan hasil perhitungan analisa produktifias suatu pekerjaan proyek bangunan bertingkat yang efisien.

\section{UCAPAN TERIMAKASIH}

Dalam penyusunan artikel ini, penulis ucapkan terimakasih kepada dosen pembimbing dan Universitas Kadiri. Penulis berharap agar artikel ini dapat bermanfaat bagi pembaca. 


\section{DAFTAR PUSTAKA}

[1] A. I. Candra, "Analisis Daya Dukung Pondasi Strauss Pile pada Pembangunan Gedung Mini Hospital Universitas Kadiri,” Ukarst, vol. 1, no. 1, pp. 63-70, 2017.

[2] A. I. Candra, A. Yusuf, and A. R. F, "Studi Analisis Daya Dukung Pondasi Tiang Pada Pembangunan Gedung Lp3m Universitas Kadiri,” CIVILLa, vol. 3, no. 2, pp. 166-171, 2018.

[3] S. Limanto, "Analisis produktivitas pemancangan tiang pancang dengan jack in pile,” no. 2, pp. 167-176, 2009.

[4] Cahyuni, "Analisa Produktivitas Alat Berat pada Proyek Pembangunan Badan jalan Tenggarong, Loa Kulu dan Loa Janan,” Tek. Sipil dan Arsit., vol. 4, no. 1, pp. 1169-1177, 2014.

[5] S. N. Indonesia, "Tata cara perhitungan harga satuan pekerjaan pondasi," p. 2836, 2002.

[6] N. D. Setiawati and A. Maddeppungeng, "ANALISIS PRODUKTIVITAS ALAT BERAT PADA PROYEK PEMBANGUNAN PABRIK KRAKATAU POSCO ZONE IV CILEGON,” J. Konstr., vol. 4, no. 2, pp. 91-103, 2013.

[7] J. F. Maquet, Construction methods and planning. 2002.

[8] B. B. Kalengkongan, T. T. Arsjad, and J. B. Mangare, "ANALISA PERHITUNGAN PRODUKTIVITAS ALAT BERAT PADA PEKERJAAN PEMATANGAN LAHAN PEMBANGUNAN TOWER SUTET LIKUPANG PANIKI," E J. Unsrat, 2018.

[9] R. A. Paulus Eric Noviyanti, "PROGRAM PERHITUNGAN EFEKTIVITAS WAKTU DAN BIAYA PEMAKAIAN TOWER CRANE," J. Dimens. Pratama, vol. 2, no. 2, pp. 1-9, 2013.

[10] W. Oetomo and Rudiansyah, "Perencanaan Penggunaan Alat Berat Dan Biaya (Studi Kasus Kegiatan Pembangunan Sekolah Terpadu Samarinda)," Fak. Tek. J. Untag, Sipil, vol. 7, no. 2, pp. 115-128, 2014.

[11] N. H. Rezky, A. Wanim, and D. P. Retno, "Analisa Penggunaan Alat Berat Pada Pekerjaan Proyek Perkerasan Jalan Kebun Durian-Gunung Sahilan-Gunung Sari Kabupaten Kampar,” E J. Unsrat, vol. 14, no. April, pp. 1-22, 2014.

[12] S. Bahri, I. R. Rahim, and A. S. Mustari, "ANALISA LIFE CYCLE COST ( LCC ) PENGADAAN ALAT BERAT DI TPA TAMANGAPA,” Univ. Hasanuddin. 
[13] S. Sosrodarsono, “Alat Alat Berat dan Penggunaannya," pp. 1-243, 1992, doi: 10.1016/S0031-9422(00)84895-5.

[14] S. F. Rostiyanti, ALAT BERAT UNTUK PROYEK KONSTRUKSI. 2008.

[15] D. D. Supit, “ANALISA PRODUKTIVITAS DAN EFISENSI ALAT BERAT UNTUK PEKERJAAN TANAH, DAN PEKERJAAN PERKERASAN BERBUTIR,” J. Dyn. Saint, 2018.

[16] I. Aoliya, P. Wiranto, and A. Mudianto, "Analisa Produktivitas Alat Berat Pada Pembangunan Jalan Ruas Lingkar Pulau Marsela Provinsi Maluku Barat Daya," JOM Tek. Sipil, vol. 1, no. 1, 2017.

[17] M. D. Agusti, E. Rita, and I. Khaidir, "Berat Pada Proyek Peningkatan Pembangunan Jalan Penggambiran Rura - Pratotang Kabupaten Pasaman Barat,” pp. 1-18, 2012.

[18] N. Mukhlisani, S. Wigjosoebroto, and I. Sudarso, "Pendekatan Structural Equation Modeling Untuk Analisa Faktor Yang Mempengaruhi Produktivitas Dari Tinjauan Keselamatan, Kesehatan, dan Lingkungan Kerja di PT. Barata Indonesia (Persero)Gresik,” Pros. Semin. Nas. Manaj. Teknol. VIII, 2008.

[19] A. Gafur, "Analisa perhitungan produktivitas alat berat pada pelaksanaan lahan untuk pembuatan work shop,” Tek. Sipil dan Arsit., vol. 1, no. 1, 2012.

[20] R. M. Sokop, T. T. Arsjad, and G. Malingkas, “Analisa Perhitungan Produktivitas Alat Berat Gali-Muat (Excavator) Dan Alat Angkut (Dump Truck) Pada Pekerjaan Pematangan Lahan Perumahan Residence Jordan Sea,” TEKNO, vol. 16, no. 70, 2018. 